\title{
BMJ Open Cost-utility analysis of antibiotic treatment in patients with chronic low back pain and Modic changes: results from a randomised, placebo-controlled trial in Norway (the AIM study)
}

To cite: Grotle M, Bråten LC, Brox Jl, et al. Cost-utility analysis of antibiotic treatment in patients with chronic low back pain and Modic changes: results from a randomised, placebocontrolled trial in Norway (the AIM study). BMJ Open 2020;10:e035461. doi:10.1136/ bmjopen-2019-035461

- Prepublication history and additional material for this paper are available online. To view these files, please visit the journal online (http://dx.doi. org/10.1136/bmjopen-2019035461).

Received 04 November 2019 Revised 19 March 2020 Accepted 12 May 2020

Check for updates

(c) Author(s) (or their employer(s)) 2020. Re-use permitted under CC BY-NC. No commercial re-use. See rights and permissions. Published by BMJ.

For numbered affiliations see end of article.

Correspondence to Professor Margreth Grotle; mgrotle@oslomet.no

\section{ABSTRACT}

Objective To evaluate the cost-utility of 100 days of antibiotics in patients with chronic low back pain (LBP) and type I or II Modic changes included in the Antibiotic treatment In patients with chronic low back pain and Modic changes (AIM) study.

Design A cost-utility analysis from a societal and healthcare perspective alongside a double-blinded, parallel group, placebo, multicentre trial.

Setting Hospital outpatient clinics at six hospitals in Norway. The main results from the AIM study showed a small effect in back-related disability in favour of the antibiotics group, and slightly larger in those with type I Modic changes, but this effect was below the pre-defined threshold for clinically relevant effect.

Participants 180 patients with chronic LBP, previous disc herniation and Modic changes type I $(n=118)$ or type II $(n=62)$ were randomised to antibiotic treatment $(n=89)$ or placebo-control $(n=91)$.

Interventions Oral treatment with either $750 \mathrm{mg}$ amoxicillin or placebo three times daily for 100 days. Main outcome measures Quality-adjusted life years (QALYs) by EuroQoL-5D over 12 months and costs for healthcare and productivity loss measured in Euro $(€ 1=N 0 K 10)$, in the intention-to-treat population. Costutility was expressed in incremental cost-effectiveness ratio (ICER).

Results Mean (SD) total cost was $€ 21046$ (20 105) in the amoxicillin group and $€ 19076$ (19 356) in the placebo group, mean difference $€ 1970$ (95\% Cl; -3835 to 7774). Cost per QALY gained was $€ 24625$. In those with type I Modic changes, the amoxicillin group had higher healthcare consumption than the placebo group, resulting in $€ 39425$ per QALY gained. Given these ICERs and a willingness-to-pay threshold of $€ 27500$ (NOK 275000 ), the probability of amoxicillin being cost-effective was $51 \%$. Even when the willingness-to-pay threshold increased to $€ 55000$, the probability of amoxicillin being cost-effective was never higher than $53 \%$.
Strengths and limitations of this study

- This is the first cost-utility study of antibiotic treatment versus placebo in patients with chronic low back pain and Modic changes.

- Amoxicillin treatment showed no evidence of being cost-effective during 1-year follow-up. This finding is in accordance with the main results of the AIM study.

- The majority of the total costs were due to production loss; costs due to healthcare had only a minor impact.

- This health economy analysis used a placebocontrol instead of usual care as a comparison group. However, the placebo group resembles usual care in previous studies from Norway.

- Costs related to adverse events and MRI were not directly assessed, but these were recorded indirectly in the monthly registrations of healthcare consumption.

Conclusions Amoxicillin treatment showed no evidence of being cost-effective for people with chronic LBP and Modic changes during 1-year follow-up.

Trial registration number ClinicalTrials.gov NCT02323412.

\section{INTRODUCTION}

Low back pain (LBP) represents a major economic burden. ${ }^{12}$ In several western countries, the social and healthcare costs related to LBP are enormous. ${ }^{3-5}$ The economic burden of LBP can be compared with other high-cost conditions such as cardiovascular disease, cancer and mental disorders. ${ }^{6} \mathrm{LBP}$ is the most common reason for seeking healthcare services in Norway, ${ }^{7}$ and chronic LBP 
is the major reason for sickness absence and disability pension. ${ }^{8}$ As in other Western countries, production loss accounts for the majority of costs due to LBP in Norway. ${ }^{3-5} 8$

The recent Lancet series claims that many of the procedures and treatments provided for LBP are lowvalue care. ${ }^{9}$ Low-value care is procedures and treatments that provide little or no benefit to patients yet increase the cost of healthcare as well as social costs due to productivity loss. In order to reduce expenditure on low-value care for LBP and help decision-makers prioritise the allocation of scarce resources to highvalue care, knowledge regarding the relative efficacy of treatments is necessary. Economic evaluations, in which the incremental effects and incremental costs of two or more interventions are compared, should be included when informing decision-makers about new treatment options for LBP.

Antibiotic treatment for chronic LBP with Modic changes was suggested as a radical new treatment option for these patients. ${ }^{10}$ Modic changes are signal changes in the vertebral bone marrow extending from the endplate $^{11}$ and are classified into types I (oedema type), II (fatty type) and III (sclerotic type, less common). ${ }^{12}$ Approximately $40 \%-50 \%$ of patients with non-specific LBP have Modic changes, but their clinical relevance is unclear. ${ }^{13}$ One hypothesis is that Modic changes and LBP may be due to a low-grade bacterial infection. A placebo controlled randomised trial ${ }^{10}$ reported substantial effect of 100 days of high-dosage antibiotic treatment on painrelated disability in patients with chronic LBP and type I Modic changes. The recent AIM replication study ${ }^{14}$ from Norway found a small, but not clinically important benefit of amoxicillin vs placebo on pain-related disability for patients with type I or type II Modic changes. In patients with type I Modic changes the benefit was slightly better, but still not clinically important.

The increasing number of published economic evaluations of interventions for chronic $\mathrm{LBP}^{15}{ }^{16}$ support the cost-effectiveness of guideline-endorsed treatments such as exercise, interdisciplinary rehabilitation, cognitive-behavioural therapy, acupuncture and spinal manipulation for people with sub-acute or chronic LBP. To our knowledge, there is no cost-effectiveness analysis of treatments for chronic LBP with Modic changes. This type of analysis was not reported in the previous trial, but was included in the present AIM study. Therefore, the purpose of this study was to use AIM data to evaluate cost-utility during 1-year follow-up of 100 days of antibiotics in patients with chronic LBP and type I or type II Modic changes. The specific research questions were:

1. What is the total cost per quality-adjusted life year (QALY) of providing 100 days of antibiotics compared to placebo in the total patient group during the intervention period (baseline to week 13) and 1 year (baseline to week 52)?

2. What is the total cost per QALYs in the subgroup of patients with type I Modic changes?

\section{METHODS}

\section{Study design, material and treatment}

This study is a cost-effectiveness analysis embedded in the AIM study; a multicentre, randomised, double-blind, placebo-controlled, parallel-group trial with a treatment phase (100 days) and a follow-up phase (from day 101 to day 365). The details of the AIM study design, recruitment, randomisation, blinding and data collection are provided in the trial protocol ${ }^{17}$ and the report on clinical results. ${ }^{14}$ Briefly, the trial was conducted at six hospitals across Norway. Patients were randomised to either amoxicillin or placebo, stratified on Modic changes type (I/ II) and previous disc surgery with a 1:1:1:1 allocation and random block sizes of 4 and 6 . The sample size was calculated to assess the treatment effect separately for type I and type II Modic changes subgroups. ${ }^{17}$

The patients were randomised to 100 days of oral treatment with either $750 \mathrm{mg}$ amoxicillin or placebo three times daily. All randomised patients started on the study medication and were included in the intention-to-treat (ITT) analysis. Patients were permitted to continue with their usual LBP therapy (eg, exercises, physiotherapy, analgesics) but were encouraged not to start additional treatments and to avoid non-steriodal anti-inflammatory drugs (NSAIDs). All adjunctive therapy was registered.

The trial was performed in accordance with the Declaration of Helsinki and the ICH-GCP (Good Clinical Practice), and registered at ClinicalTrials.gov in December 2014. Methods were unchanged after trial commencement.

\section{Treatment effect and utilities}

To measure treatment effects and health utilities the EuroQoL 5D (EQ-5D-5L) utility index was used. ${ }^{18}$ The EQ-5D-5L is a generic and preference-weighted measure of health-related quality-of-life based on five dimensions: mobility, self-care, activities of daily life, pain and anxiety and/or depression. For each dimension, the patient assesses five possible levels of problems (from none to severe). The participants completed the EQ-5D-5L at baseline, after 100 days of treatment (week 13) and at 12 month follow-up (week 52). Health gains were expressed as QALYs, which were derived from the EQ-5D-5L utility scores, using the UK tariff. ${ }^{19}$ A Norwegian tariff is not available. QALYs range from -0.59 to 1 , where one corresponds to perfect health, and -0.59 to worst imaginable health. Combining utility indexes and time, the QALYs were estimated as area under the curve using the trapezoidal method. ${ }^{20}$

The willingness-to-pay (WTP) threshold for LBP was based on the Norwegian governmental report No. 34 to the parliament with a value of NOK $275000(€ 27500 /$ US $\$ 35628$ ) per QALY (Norwegian Ministry of Health and Care Services, 2016).$^{21}$

\section{Costs of healthcare and production loss}

Healthcare utilisation, including medication, and work loss were reported each month throughout the whole 
study period in the web-based data capture system (Viedoc) that was used in the AIM study: during the treatment period until first follow-up week 13, it was filled in by the treating doctor and from week 14 until week 52 it was filled in by self-report of the participants. The registration included number of visits to a general practitioner, medical specialist, physical therapist, manual therapist or other physical therapy specialist, and other therapists (specified); number of days of hospitalisation and/or rehabilitation; use of medication (both prescription and over-the-counter medication) and type of medication (name of medication, dosage). The monthly registration also contained information about work loss which included work status in terms of working time (percentage of position), partial sick leave (percentage, duration and reason), complete sick leave (duration and reason), disability pension (percentage, duration and reason), unemployment (yes, no) and student/other/ unknown (yes, no). Use of healthcare due to adverse events was also registered. We did not assess distance and transportation related to the healthcare utilisation and, hence, could not calculate transportation costs.

Costs were estimated on a present-value basis of the Euro in 2019, using the exchange rate from 2019 (September: $€ 1=$ NOK 10). Analysis included healthcare and societal perspectives, the latter including costs due to healthcare and productivity loss. Cost categories, units, valuation and unit price are presented in table 1. Costs for the antibiotic medication were valued using unit prices from the Norwegian Medicines Agency. ${ }^{22}$ Pharmacy Selling Price

Table 1 Cost categories, units, valuation and unit price, all numbers in Euros and NOK for 2019

\begin{tabular}{|c|c|c|c|c|c|}
\hline Cost categories & Unit & Valuation & $\begin{array}{l}\text { Unit } \\
\text { price }(€)\end{array}$ & $\begin{array}{l}\text { Unit } \\
\text { price } \\
\text { (NOK) }\end{array}$ & Reference (source) \\
\hline $\begin{array}{l}\text { Direct costs of antibiotic } \\
\text { treatment (amoxicillin } 750 \mathrm{mg} \\
\text { three times daily for } 100 \text { days) }\end{array}$ & Per patient & Cost & 311.5 & 3115 & $\begin{array}{l}\text { NOMA price list, Imacillin TevaAmoksicillin } \\
\text {-trihydrat, NOK } 207.70 \text { per } 20 \text { tbl a } 750 \\
\text { mg) }\end{array}$ \\
\hline $\begin{array}{l}\text { Direct costs of placebo } \\
\text { treatment (placebo three times } \\
\text { daily for } 100 \text { days) }\end{array}$ & Per patient & Cost & 0 & 0 & $\begin{array}{l}\text { Not available at pharmacies, so the price set } \\
\text { is } 0 . \text { (The cost produced for this study was } \\
\text { NOK } 470 .)\end{array}$ \\
\hline $\begin{array}{l}\text { Non-opioid medication } \\
\text { (NSAIDs:ibuprofen, paracetamol, } \\
\text { other A-prescription medicines) }\end{array}$ & $\begin{array}{l}\text { Per daily } \\
\text { defined dose }\end{array}$ & Cost & 1.6 & 16 & Pharmacy selling price (over-the-counter) \\
\hline Opioid medication (codein) & $\begin{array}{l}\text { Per daily } \\
\text { defined dose }\end{array}$ & Cost & 3.0 & 30 & Pharmacy selling price \\
\hline General practitioner* & Per visit & Cost & 45.8 & 458 & NOMA, general practitioner consultation \\
\hline Medical specialist & Per visit & Cost & 86 & 860 & $\begin{array}{l}\text { NOMA, specialist health service } \\
\text { consultation (fee* } 2,+20 \mathrm{~min})\end{array}$ \\
\hline Chiropractor & Per visit & Cost & 50 & 500 & $\begin{array}{l}\text { Norsk Kiropraktorforening estimated } \\
\text { average }\end{array}$ \\
\hline Physiotherapist & Per visit & Cost & 25 & 250 & $\begin{array}{l}\text { The Norwegian Physiotherapy Association, } \\
\text { estimated average }\end{array}$ \\
\hline Manual therapist & Per visit & Cost & 41.9 & 419 & $\begin{array}{l}\text { The Norwegian Physiotherapy Association, } \\
\text { estimated average }\end{array}$ \\
\hline Psychomotoric physiotherapy & Per visit & Cost & 41.9 & 419 & $\begin{array}{l}\text { The Norwegian Physiotherapy Association, } \\
\text { estimated average }\end{array}$ \\
\hline Acupuncture & Per visit & Cost & 75 & 750 & Average estimate from private price lists \\
\hline Other therapists & Per visit & Cost & 75 & 750 & Average estimate from private price lists \\
\hline Back surgery (fusion) & Per surgery & Cost & 9621.4 & 96214 & DRG215B \\
\hline Hospitalisations (non-surgery) & Per day & Cost & 1140 & 11400 & DRG247 (/2) per patient \\
\hline Rehabilitation stay (outpatient) & Per day & Cost & 300 & 3000 & $\begin{array}{l}\text { UniCare price list, adjusted for health region } \\
\text { authority supplements }\end{array}$ \\
\hline $\begin{array}{l}\text { Production loss ( } 225 \text { work days } \\
\text { per year) }\end{array}$ & Per day & $\begin{array}{l}\text { Wage rate } \\
\text { adjusted } \\
\text { for age and } \\
\text { gender }\end{array}$ & 246.3 & 2463 & Statistics Norway ${ }^{83}$ \\
\hline
\end{tabular}

${ }^{*}$ Costs varied in multiway sensitivity analysis (Tornado diagram): GP, other healthcare costs, production loss (-20 /+20\%). The cost of antibiotic treatment varied $-50 \% /+20 \%$, as amoxicillin is a generic product and the price is expected to decrease in the future. NOMA, Norwegian Medicines Agency; NSAID, non-steriodal anti-inflammatory drug. 
was used (with VAT included). Costs due to other healthcare consumption related to LBP were estimated based on data from the monthly registrations. Number of days of sick leave due to LBP was calculated for each month and adjusted for part-time work (employment rate), as well as percentage sick leave in the period. The costs of productivity loss were estimated as the number of days absent from work multiplied by the average wage rate in Norway by sex. Costs for absence from work were estimated from official statistics of average wage by sex and age groups, ${ }^{823}$ including social costs of $40 \%$ and adjusted for employment and sick leave rate.

\section{Statistical analysis}

The baseline characteristics of intervention and control group participants were compared with those of participants with complete and incomplete data using descriptive statistics. Student's t-tests and corresponding 95\% CIs were used to analyse differences in costs, and Analysis of Covariance (ANCOVA) was used to analyse differences in utilities with adjustment for baseline score, the six hospitals, physical workload and use of healthcare at baseline (which were unequally distributed across the two groups at baseline). An incremental cost-effectiveness ratio (ICER) was calculated, defined by the incremental costs (costs in the antibiotic group - costs in the placebo group) relative to QALYs gained (QALYs antibiotic group - QALYs placebo group). Differences between the two groups in QALYs gained were estimated using the trapezoidal method (the area under the curve combining utility indexes and time).$^{20}$ Uncertainty was analysed using the bootstrap method with 10000 replicated datasets.

To illustrate the statistical uncertainty surrounding ICERs, the bootstrapped cost and effect pairs were plotted on a cost-effectiveness plane (CE plane) with the ICERs on the $\mathrm{y}$-axis and the incremental effects on the $\mathrm{x}$-axis. The CE plane is divided into four quadrants; when the ICERs cluster in the south-east quadrant the intervention is less costly with an improved health gain (the intervention is considered dominant over the comparator); the south-west quadrant reflects a less costly intervention but a worse health gain, whereas the north-east indicates a costlier intervention but with an improved health gain. This represents a 'trade-off' situation, in which increases in cost must be compared with improvements in health (north-east quadrant); assuming WTP for an additional QALY, one can see whether the treatment is cost-effective (under the cost-effectiveness WTP threshold) or not (if above WTP threshold). The north-west quadrant reflects a more costly intervention with a poorer health gain (the intervention is considered to be dominated by the comparator). Cost-effectiveness acceptability curves (CEAC) were used to demonstrate the probability that antibiotics are cost-effective in comparison to placebo for a range of different WTP values.

The ITT method was used. There were little missing data, and missing values were imputed with a multiple imputation model described in the published protocol. ${ }^{17}$
To assess the robustness of the results, the following sensitivity analyses were carried out:

1. Complete case analysis (without adjustment for missing data).

2. Without outliers (one patient who had surgery plus hospital stay, one patient with hospital stay (without surgery) and two patients with 3 weeks of rehabilitation stay).

3. Uncertainty of the ICER was tested by bootstrapping with 10000 repetitions (probabilistic sensitivity analysis).

4. In a multiple one-way sensitivity analysis, the relevant costs and QALYs were varied 20\% below and above the estimate given in table 1 . The cost of antibiotics was varied $-50 \% /+20 \%$ due to expected price decrease (generic medicine). Results are presented in a Tornado diagram showing the number of one-way sensitivity analyses in one graph.

\section{Patient and public involvement}

A patient representative was a member of the Scientific Board of the study, which effected all the major decision from planning and design of the study, to the dissemination of the study results. The patient representative assessed the burden of the study medication and the time and efforts required to participate in the trial. We will disseminate the results to study participants and the patient organisation (Norwegian Back Pain Association) in advance of publication.

\section{RESULTS}

\section{Patients}

From June 2015 to September 2017, 180 patients (118 with type I Modic changes and 62 with type II Modic changes) were randomised to receive amoxicillin $(\mathrm{n}=89)$ or placebo $(n=91)$. Demographic and clinical characteristics at baseline are shown in table 2. There were only minor differences between the two groups in baseline characteristics (age, gender, comorbidity, former disc surgery, Modic changes type, pain duration, pain intensity, disability, quality-of-life and work status), whereas a slightly larger difference was found in the use of healthcare in the month prior to inclusion and in physical workload. Compared with the placebo group, patients receiving amoxicillin reported more use of healthcare and less physical workload.

\section{Missing data}

Three patients had incomplete data on any of the monthly registrations of healthcare consumption during the year of follow-up, whereas six lacked data on productivity loss. A total of eight patients had incomplete data in the EQ5D-5L. Details of missing data are provided in the online supplementary appendix A.

\section{Cost-utility}

The costs in both groups during the intervention period and follow-up period are provided in table 3. Costs were 
Table 2 Baseline characteristics of participants in the treatment groups and for those with type I MCs

\begin{tabular}{|c|c|c|c|c|}
\hline & $\begin{array}{l}\text { Amoxicillin } \\
(n=89)\end{array}$ & Placebo $(n=91)$ & $\begin{array}{l}\text { Type I MCs } \\
\text { amoxicillin } \\
(n=60)\end{array}$ & $\begin{array}{l}\text { Type I MCs } \\
\text { placebo } \\
(\mathrm{n}=58)\end{array}$ \\
\hline Age (mean (SD)) & $44.7(9.0)$ & $45.2(9.0)$ & $46.0(9.3)$ & $44.9(9.3)$ \\
\hline Women & $53(60)$ & $52(57)$ & $35(58)$ & $35(60)$ \\
\hline Smoking, yes & $25(28)$ & $21(24)$ & $13(22)$ & $18(31)$ \\
\hline Previous disc surgery & $18(20)$ & $20(22)$ & $12(20)$ & $10(17)$ \\
\hline \multicolumn{5}{|l|}{ Educational level } \\
\hline Primary school (9 years) & $10(11)$ & $9(10)$ & $4(6.7)$ & $8(14)$ \\
\hline High school (12 years) & $36(41)$ & $42(47)$ & $27(45)$ & $21(36)$ \\
\hline College or university (<4 years) & $27(31)$ & $18(20)$ & $11(18)$ & $17(29)$ \\
\hline University ( $\geq 4$ years) & $15(17)$ & $20(22)$ & $16(27)$ & $11(19)$ \\
\hline \multicolumn{5}{|l|}{ Employment status } \\
\hline Working full time & $46(52)$ & $43(47)$ & $33(57)$ & $32(53)$ \\
\hline Partial sick leave & $14(16)$ & $20(22)$ & 7 (12) & $11(19)$ \\
\hline Complete sick leave & $22(25)$ & $16(18)$ & $14(24)$ & $11(19)$ \\
\hline Disability pension & $3(3)$ & $7(8)$ & $3(5)$ & $2(3)$ \\
\hline Unemployed & $2(2)$ & $3(3)$ & $1(2)$ & $2(3)$ \\
\hline Student/other/unknown & $2(2)$ & $2(2)$ & 0 & $2(3)$ \\
\hline \multicolumn{5}{|l|}{ Physical workload } \\
\hline Mostly sitting & $37(48)$ & $26(35)$ & $18(30)$ & $28(48)$ \\
\hline Job requires a lot of walking & $20(26)$ & $20(27)$ & $14(23)$ & $12(21)$ \\
\hline Job requires a lot of walking and lifting & $17(22)$ & $24(32)$ & $13(22)$ & $9(16)$ \\
\hline Job requires physically heavy work & $3(4)$ & $4(5)$ & $4(6.7)$ & $2(3.4)$ \\
\hline \multicolumn{5}{|l|}{ Comorbidity* } \\
\hline Score 1 (back pain only) & $62(70)$ & $60(66)$ & $40(67)$ & $40(69)$ \\
\hline Score 2 & $21(24)$ & $27(30)$ & $17(28)$ & $13(22)$ \\
\hline Score $>2$ & $6(7)$ & $4(4)$ & $3(5.0)$ & $5(8.6)$ \\
\hline Use of healthcare in the month prior to inclusion & $24(27)$ & $15(17)$ & $17(29)$ & $10(17)$ \\
\hline \multicolumn{5}{|l|}{ Use of medication the month prior to inclusion } \\
\hline Non-opioid medication & $46(52)$ & $52(57)$ & $30(52)$ & $34(57)$ \\
\hline Opioid medication & $28(32)$ & $26(29)$ & $17(29)$ & $10(17)$ \\
\hline Duration of back pain in years (median (IQR)) & $3.0(1.5-5.6)$ & $3.4(1.7-7)$ & $4(2-8)$ & $2.8(1.5-5.2)$ \\
\hline Back pain intensity $(0-10)$ & $6.4(1.2)$ & $6.3(1.5)$ & $6.5(1.1)$ & $6.3(1.3)$ \\
\hline Roland-Morris Disability Questionnaire (0-24) & $12.7(4.7)$ & $12.8(3.7)$ & $12.9(4.3)$ & $12.3(3.7)$ \\
\hline EQ-5D-5L (-0.59-1) & $0.55(0.19)$ & $0.54(0.18)$ & $0.55(0.18)$ & $0.56(0.16)$ \\
\hline
\end{tabular}

$\mathrm{N}$ refers to the number of patients providing data.

Values are no/total no (\%) unless stated otherwise.

${ }^{*}$ Functional Comorbidity Index ${ }^{33}$ - Score increased by 1 for each 18 diagnoses associated with decreased physical function.

MC, Modic changes.

mainly related to productivity loss, accounting for $96 \%$ of the total costs in the amoxicillin group and $98 \%$ in the placebo group, amounting to $€ 20091$ and $€ 18774$, respectively. The mean healthcare costs were approximately threefold in the amoxicillin group as in the placebo group during the follow-up year, with an average of $€ 955$ vs $€ 302$, respectively. The online supplementary appendix A and B provide more details regarding number of patients and type and frequency of healthcare consumption during follow-up. In particular, the use of physiotherapy and manual therapy was substantially higher in the amoxicillin group. The costs due to production loss were more equally distributed across the two groups (table 3). In total, the sum of all costs was $€ 1970$ higher in the amoxicillin group than in the placebo group (95\% CI $€-3835$ to $€ 7774$ ) (table 4 ). In the subgroup 


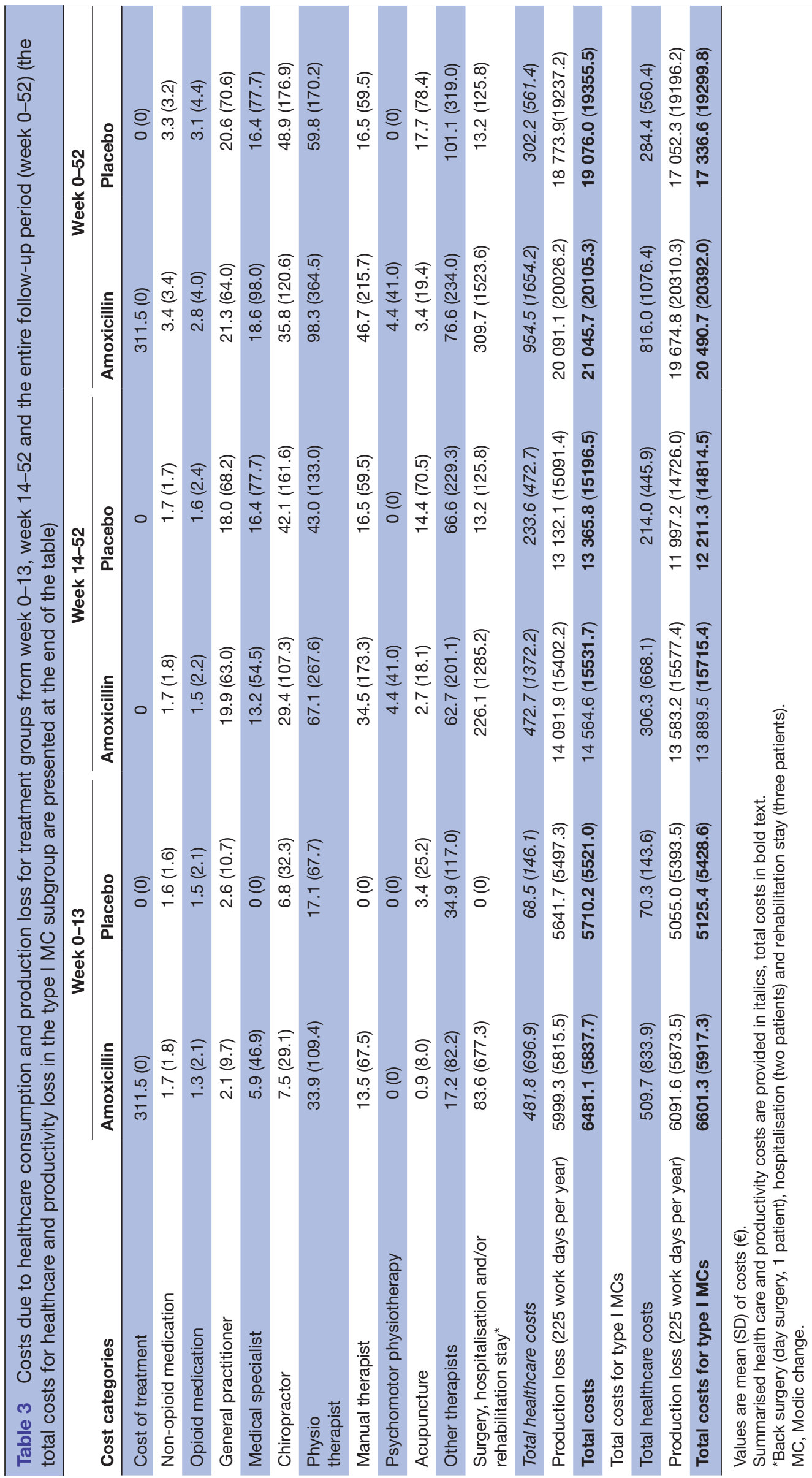


Table 4 Differences in mean costs $(€)$ and utilities (QALYs) with 95\% Cl and ICER during the intervention period (week 0-13) and the whole period (week 0-52)

\begin{tabular}{|c|c|c|c|}
\hline & $\begin{array}{l}\Delta \text { costs } \\
(95 \% \mathrm{Cl})\end{array}$ & $\begin{array}{l}\triangle \text { QALYs } \\
(95 \% \mathrm{Cl})^{*}\end{array}$ & $\begin{array}{l}\text { Mean incremental cost per } \\
\text { QALY gained (ICER } \dagger \text { ) }\end{array}$ \\
\hline \multicolumn{4}{|l|}{ Healthcareł } \\
\hline Week 0-13 & 413 (266 to 561$)$ & $0.04(-0.02$ to 0.09$)$ & \\
\hline Total 0-52 & 652 (291 to 1014) & $0.08(0.02$ to 0.14$)$ & 8150 \\
\hline \multicolumn{4}{|c|}{ Productivity loss $\ddagger$} \\
\hline Week 0-13 & 358 (-1307 to 2022$)$ & $0.04(-0.02$ to 0.09$)$ & \\
\hline Total 0-52 & $1317(-4458$ to 7093$)$ & 0.08 (0.02 to 0.14$)$ & 16463 \\
\hline \multicolumn{4}{|c|}{ Total main analysis $\ddagger$} \\
\hline Week 0-13 & 771 (-900 to 2442$)$ & $0.04(-0.02$ to 0.09$)$ & \\
\hline Total 0-52 & $1970(-3835$ to 7774$)$ & $0.08(0.02$ to 0.14$)$ & 24625 \\
\hline \multicolumn{4}{|c|}{ Healthcare, type I MCs§ } \\
\hline Week 0-13 & 439 (223 to 656$)$ & $0.05(-0.01$ to 0.12$)$ & \\
\hline Total 0-52 & 532 (220 to 843$)$ & 0.08 (0.01 to 0.15$)$ & 6650 \\
\hline \multicolumn{4}{|c|}{ Productivity loss, type I MCs§ } \\
\hline Week $0-13$ & $1037(-1019$ to 3092$)$ & $0.05(-0.01$ to 0.12$)$ & \\
\hline Total 0-52 & 2623 (-4581 to 9826$)$ & 0.08 (0.01 to 0.15$)$ & 32788 \\
\hline \multicolumn{4}{|c|}{ Total type I Modic changes $\S$} \\
\hline Week 0-13 & $1476(-594$ to 3545$)$ & 0.05 (-0.01 to 0.12$)$ & \\
\hline Total 0-52 & 3154 (-4083 to 10392$)$ & 0.08 (0.01 to 0.15$)$ & 39425 \\
\hline \multicolumn{4}{|c|}{ Complete case analysisף } \\
\hline Week 0-13 & 872 (-845 to 2590$)$ & $0.05(-0.01$ to 0.10$)$ & \\
\hline Total 0-52 & 2129 (-3823 to 8082$)$ & $0.08(0.02$ to 0.14$)$ & 26613 \\
\hline \multicolumn{4}{|c|}{ Without outliers ${ }^{\star *}$} \\
\hline Week 0-13 & 792 (-907 to 2491$)$ & $0.04(-0.02$ to 0.09$)$ & \\
\hline Total 0-52 & $1838(-4089$ to 7765$)$ & 0.08 (0.02 to 0.14$)$ & 22975 \\
\hline
\end{tabular}

*QALYs based on EuroQol's health-related quality of life measure (EQ-5D-5L) with scores from -0.59 to 1 . Higher scores indicating better quality of life. Differences are adjusted for baseline scores, the six study sites and use of healthcare and workload prior to inclusion. †ICER = (Costs Amoxicillin arm - Costs Placebo arm) / (QALY Amoxicillin arm - QALY Placebo arm). $\ddagger$ Main analysis by intention-to-treat $(n=180)$. §Including only type I Modic changes $(\mathrm{n}=118)$.

ПComplete case analysis without adjustment for missing data $(n=$.

${ }^{* *}$ Sensitivity analysis by excluding five outliers ( $\left.n=175\right)$ (ID3002, ID3018, ID3019, ID3029, ID4015).

ICER, incremental cost-effectiveness ratio; QALY, quality-adjusted life year.

of patients with type I Modic changes the costs due to productivity loss and healthcare were slightly higher in the amoxicillin group with a mean difference in total costs of $€ 3154$ (95\% CI $€-4083$ to $€ 10392)$ (table 4).

At 1-year follow-up, there was a statistically significant difference in QALYs in favour of the amoxicillin group of mean 0.08 (95\% CI 0.02 to 0.14$)$ (table 4$)$. This mean difference of 0.08 was also found when analyses were repeated without adjustment for missing data and without outliers (table 4 ). The ICER for the main analysis was $€ 24621$. In the subgroup of patients with type I Modic changes, the ICER was $€ 39427$.

The cost-effectiveness plane (figure 1) displays the bootstrapped total cost and the differences in QALYs gained between amoxicillin and placebo with a WTP threshold of $€ 27500$. Samples are slightly skewed towards the right with a similar distribution in the northeast and southeast quadrants. Figure 2 shows the CEAC curve, which presents the probability that amoxicillin is cost-effective compared with placebo for a range of different WTP thresholds. At a willingness-to-pay threshold of $€ 27500$, the probability of amoxicillin being cost-effective was $51 \%$. Even when the WTP threshold was increased to $€ 55000$, the probability of amoxicillin being cost-effective was never higher than $53 \%$.

The multiple univariate sensitivity analyses showed that productivity loss had the highest impact on the ICER in both treatment arms (figure 3). Even altering the cost of amoxicillin to $50 \%$ below the current estimate did not affect the ICER significantly. 


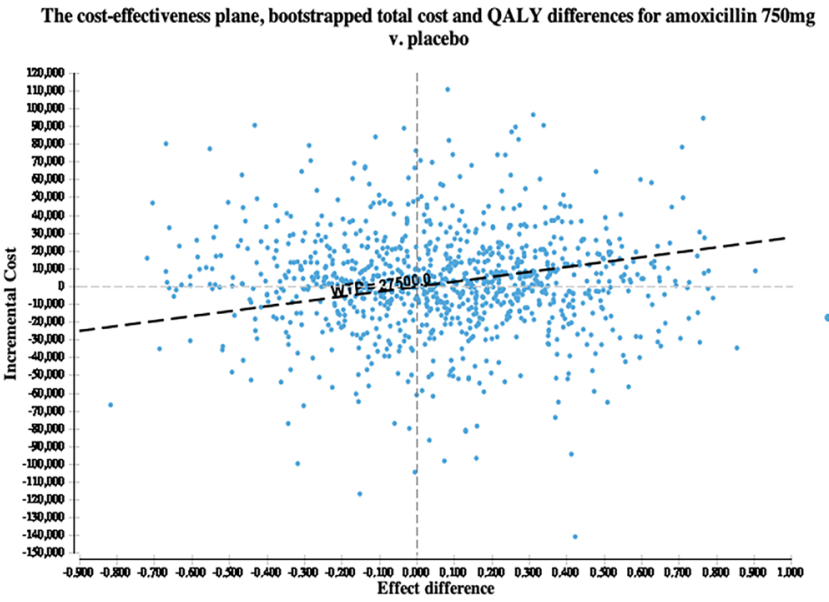

Figure 1 Cost-effectiveness plane. Each dot ( $n=10000)$ represents a bootstrapped incremental cost-effectiveness ratio. QALY, quality-adjusted life years; WTP, willingness-topay.

\section{DISCUSSION}

\section{Principal findings}

This health economic evaluation showed that 100 days of amoxicillin treatment is unlikely to be cost-effective for patients with LBP and Modic changes. Over the 1-year study period, the cost-effectiveness ratio was $€ 24621$ per QALY gained for the total group, including patients with type I and type II Modic changes. In the type I Modic changes subgroup, the ICER was €39 427 per QALY gained. The sensitivity analyses supported these findings. The probability of amoxicillin being cost-effective never exceeded $53 \%$.

Our results support the main results from the AIM study which detected no clinically important benefit of amoxicillin compared to placebo during 12 months of follow-up. ${ }^{14}$ The present cost-utility analysis also extends the findings from the AIM study by demonstrating that the patients in the amoxicillin group used more healthcare than the placebo group. In particular, the use of physiotherapy and manual therapy was substantially higher in the amoxicillin group. Both physiotherapy and manual therapy are found to affect pain and disability as well as

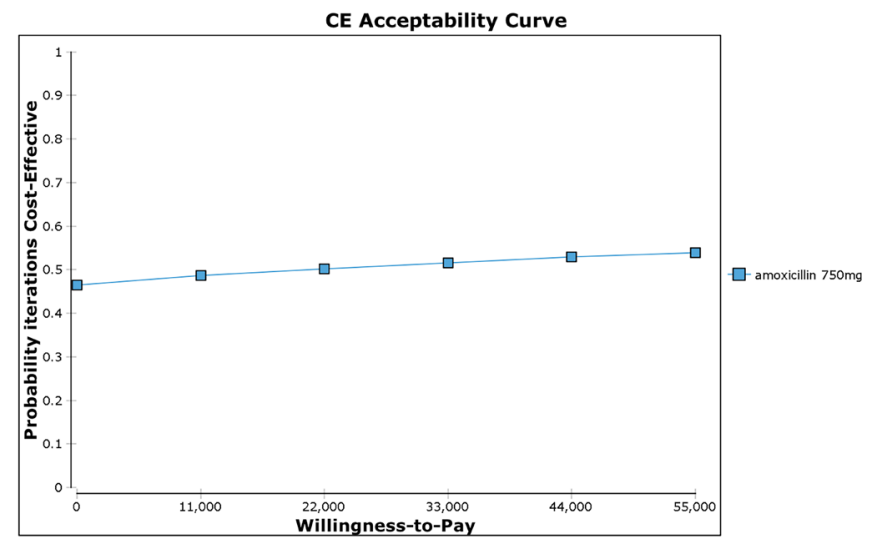

Figure 2 The cost-effectiveness acceptability curve.

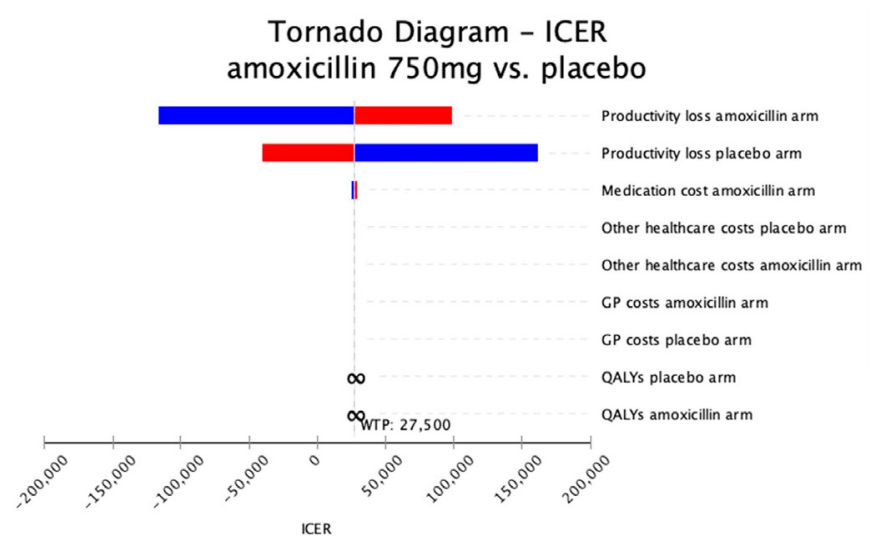

Figure 3 Tornado diagram (number of one-way sensitivity analyses presented in one graph). ICER, incremental costeffectiveness ratio; QALY, quality-adjusted life year; WTP, willingness to pay.

health-related quality-of-life outcomes in chronic LBP. ${ }^{24}$ Consequently, the differences observed in the EQ-5D-5L scores, and thus in the QALYs, might be an overestimation of the true treatment effect of amoxicillin.

When considering the threshold value of the ICER, or society's WTP for a QALY, it is important to acknowledge the denominator of this ratio. A QALY gain of 0.05 to 0.08 , which was found in the present analyses, is only slightly higher than the average QALY gain of exercise therapy compared to usual care in subacute and chronic LBP. $^{25}$ The QALY gained in the present study translates to approximately 3 weeks in best imaginable health. ${ }^{26}$ Our findings are very similar to findings in a systematic review of all cost-utility analyses published in 2010; in 370 studies the median incremental QALY gain (as mainly measured by the EQ5D-3L) was $0.06{ }^{26}$ This review also found larger gains in studies in which the comparator was placebo or no-treatment. Despite the use of placebo as comparator in our study, we did not achieve larger QALY gains than 0.08 .

Another important point to consider is the perspective of clinical importance of the QALY gained in the amoxicillin group compared to the placebo group. According to a systematic review estimates for the QALY, minimal clinical important difference varies from 0.03 to 0.54 with an average estimate of $0.18 .^{27}$ Similarly, a Norwegian study of patients with chronic LBP and degenerative disc disease reported a minimal clinically important (within-group) change estimate for the EQ-5D-5L of $0.17 .^{28}$ Although the wide variation around mean values of QALY gains indicates that some individuals have larger gains than others, our findings are in line with the minor effects of most interventions for LBP. Two recent systematic reviews of health-economic effects of exercises ${ }^{26}$ and multidisciplinary rehabilitation ${ }^{29}$ for LBP, showed similar small estimates of QALYs gained but to different costs, depending on in which country the trial was conducted.

The suggested WTP threshold in Norway was NOK 275 000 (€27 500) per QALY in 2016 for the lowest severity 
grade patients. ${ }^{21}$ There is no consensus about the acceptable maximum costs per QALY gained, but the Norwegian WTP threshold is quite similar to the National Institute for Health and Care Excellence (NICE) threshold (£20 000-£30 000). ${ }^{30}$ The NICE threshold is commonly used to provide an indication of cost-effectiveness across international studies. Recent evidence indicates that the WTP threshold may vary depending on the severity and the prevalence of the disease. ${ }^{15}$ LBP is not generally a very serious disease, but it is prevalent and has a high impact on productivity loss and societal costs. Accordingly, more than $95 \%$ of the total costs in the present study were due to productivity loss.

\section{Limitations}

A weakness of this health economy analysis is the use of a placebo instead of usual care as a comparison group. Due to the scarcity of resources, decision-makers have to compare different alternatives before deciding which one to fund. When a placebo is chosen as a comparator instead of active treatment, the level for determining the therapeutic and economic advantage might be lower. Studies using placebo or no-treatment as a comparator have shown larger QALY gains than studies using usual care as a comparator. ${ }^{26}$ However, except for a request to avoid NSAIDs, both groups were permitted to continue with usual care. Therefore, we believe the use of healthcare in the placebo group resembles usual care in Norway. In a previous study on patients with chronic LBP in which the control group received usual care, the 1-year mean healthcare costs, including primary and secondary care and medication, was approximately NOK 2000 per patient (2012-prices, equals approximately $€ 200) .{ }^{31}$ This is similar to the mean healthcare costs during follow-up in our placebo group (€234 or NOK 2336 per patient).

Another limitation is that costs related to antibiotic resistance were not included in these analyses. We did not specifically record costs related to adverse events, but these were recorded indirectly in the monthly registrations of healthcare consumption. We did record the use of MRI and other imaging during the follow-up period. However, there were only minor differences between the groups with regard to medical specialist consultations and imaging (see online supplementary appendix A and B), and it is unlikely that their associated costs would influence the main results. The majority of the total costs in this study were due to production loss; costs due to healthcare had only a minor impact.

Finally, a 1-year horizon was chosen for the present costutility analysis since this study is an extension of the AIM Study. The cost-utility analysis might have been stronger if we modelled in a longer time horizon, for example, in a 5 -year time horizon. A longer time horizon has been found to increase QALY gains. ${ }^{26}$

\section{Comparisons with other health-economic studies on chronic LBP}

There is little evidence on cost-utility of medications for chronic LBP. Such evidence was neither found in two systematic reviews from 2011 in which trials with cost-effectiveness evaluations of guideline-endorsed treatments ${ }^{16}$ and GP care ${ }^{15}$ for LBP were summarised, nor in the two recent systematic reviews of the health-economic effects of exercises ${ }^{25}$ and multidisciplinary rehabilitation ${ }^{29}$ for LBP. To our knowledge, there is no cost-effectiveness or cost-utility study on pharmacotherapy for chronic LBP, with or without Modic changes. Hence, our results cannot be directly compared with other studies. In the scientific LBP literature, information on drug costs is often missing, and the general lack of high-quality economic evaluations in LBP has been thoroughly documented. ${ }^{32}$ The high economic burden of chronic LBP underlines the need for high-quality economic evaluations of new treatments, in particular those with a potential for side effects and safety issues. Antibiotics are a new treatment for chronic LBP, and there may be a risk of antibiotic resistance and other side effects. Since Modic changes are common in patients with chronic LBP, ${ }^{13}$ and since this is the first costutility analysis of antibiotic treatment, we consider the present study to be important for researchers, clinicians and policy-makers.

\section{CONCLUSIONS AND POLICY IMPLICATIONS}

In conclusion, this cost-utility analysis on patients with chronic LBP and Modic changes has shown that amoxicillin treatment is not cost-effective compared to placebo. The probability of amoxicillin being cost-effective was never higher than 53\%, regardless of WTP. In the AIM study, in which this present analysis was embedded, amoxicillin did not provide a clinically important benefit. Our findings give further support to the notion that amoxicillin is not a cost-effective treatment for patients with LBP.

\section{Author affiliations}

${ }^{1}$ Department of Research and Innovation, Oslo University Hospital, Oslo, Norway

${ }^{2}$ Department of Physiotherapy, Oslo Metropolitan University Faculty of Health

Sciences, Oslo, Norway

${ }^{3}$ FORMI, Oslo University Hospital Ullevaal, Oslo, OSLO, Norway

${ }^{4}$ Physical Medicine and rehabilitation, 0slo University Hospital, Oslo, Norway ${ }^{5}$ Department of Radiology, Haukeland University Hospital, Bergen, Norway

${ }^{6}$ Regional Research Support Services, Oslo University Hospital Ullevaal, Oslo, Norway

${ }^{7}$ Department of Physiotherapy, Oslo Metropolitan University Faculty of Health Sciences, 0slo, Oslo, Norway

${ }^{8}$ Department of Rheumatology, Østfold Hospital Trust, 0slo, Oslo, Norway ${ }^{9}$ Department of Physical Medicine and Rehabilitation, Vestre Viken Hospital Trust, Drammen, Norway

${ }^{10}$ Department of Clinical Medicine, University of Bergen, Bergen, Hordaland, Norway

${ }^{11}$ Department of Health Sciences, VU University, Amsterdam, Netherlands

${ }^{12} \mathrm{Clinic}$ for Surgery and Neurology, FORMI, Oslo, Norway

${ }^{13}$ Department of Neurology and FORMI, Oslo University Hospital, Oslo, Norway

${ }^{14}$ Faculty of Medicine, University of Oslo, Oslo, Norway

\section{Twitter Lars Christian Bråten @LarsChrBraten}

Acknowledgements We want to thank all patients participating in the study, and Eira Kathleen Ebbs for proofreading English language of the manuscript.

Contributors MG, JIB, AE, LG, AF, KS and J-AZ designed the study together with the AIM study group. KS, J-AZ and AE contributed to the funding of the AIM study. $\mathrm{JIB}, \mathrm{LG}, \mathrm{AE}, \mathrm{AF}, \mathrm{MW}$ and PMK generated the data for the AIM study together with participants in the AIM study group. MG, LCB, RMK, AT and ZZ-K analysed the 
data. MG, JIB, AE, LG, MWvT, KS and J-AZ contributed in discussion of analyses and results presentation. MG wrote the manuscript with all authors contributing in reading, commenting and approving the final manuscript.

Funding This work was supported by the South-Eastern Norway Regional Health Authority (Helse Sør-Øst, grant no: 2015090) and Western Norway Regional Health Authority (Helse Vest, grant no: 911938 and 911891).

Disclaimer Funding organisations had no part in the planning, performing or reporting of the trial.

Competing interests KS reports that funding was granted by governmental organisations (Helse Sør-Øst and Helse Vest) during the conduct of the study

Patient and public involvement Patients and/or the public were involved in the design, or conduct, or reporting, or dissemination plans of this research. Refer to the Methods section for further details.

\section{Patient consent for publication Not required.}

Ethics approval The trial was approved by the Regional Committees for Medical Research Ethics - South East Norway (2014/158/REK sør-øst) and the Norwegian Medicines Agency (NOMA; reference no 14/01368-11; EUDRACT NO 2013004505-14) before commencing and monitored by the Clinical Trial Unit at Oslo University Hospital.

\section{Provenance and peer review Not commissioned; externally peer reviewed.}

Data availability statement Data are available upon reasonable request. Requests to access data should be addressed to kjersti.storheim@medisin.uio.no. De-identified individual participant data (including data dictionary) will be available to medical researchers by request in accordance with local registration and ethical approval, when the article has been published until 1th of July, 2029. All proposals requesting data access will need to specify an analysis plan and will need approval of the scientific board before any data can be released.

Open access This is an open access article distributed in accordance with the Creative Commons Attribution Non Commercial (CC BY-NC 4.0) license, which permits others to distribute, remix, adapt, build upon this work non-commercially, and license their derivative works on different terms, provided the original work is properly cited, appropriate credit is given, any changes made indicated, and the use is non-commercial. See: http://creativecommons.org/licenses/by-nc/4.0/.

\section{ORCID iDs}

Margreth Grotle http://orcid.org/0000-0001-8243-1143

Lars Christian Bråten http://orcid.org/0000-0002-2560-2556

Jens Ivar Brox http://orcid.org/0000-0002-2507-1812

Maurits W van Tulder http://orcid.org/0000-0002-7589-8471

\section{REFERENCES}

1 Hoy DG, Smith E, Cross M, et al. The global burden of musculoskeletal conditions for 2010: an overview of methods. Ann Rheum Dis 2014;73:982-9.

2 GBD 2016 Disease and Injury Incidence and Prevalence Collaborators. Global, regional, and national incidence, prevalence, and years lived with disability for 328 diseases and injuries for 195 countries, 1990-2016: a systematic analysis for the global burden of disease study 2016. Lancet 2017;390:1211-59.

3 Dagenais S, Caro J, Haldeman S. A systematic review of low back pain cost of illness studies in the United States and internationally. Spine J 2008;8:8-20.

4 Maniadakis N, Gray A. The economic burden of back pain in the UK. Pain 2000;84:95-103.

5 Martin BI, Deyo RA, Mirza SK, et al. Expenditures and health status among adults with back and neck problems. JAMA 2008;299:656-64.

6 Foster NE, Anema JR, Cherkin D, et al. Lancet low back pain series working $\mathrm{G}$. prevention and treatment of low back pain: evidence, challenges, and promising directions. Lancet 2018.

7 Statistics Norway. Flest til fastlegen på grunn av muskel- og skjelettlidelser, 2018.

8 Norwegian Labour and Welfare Administration. Sykefraværsstatistikk. Available: https://www.nav.no/no/NAV+og+samfunn/Statistikk/ Sykefravar+-+statistikk/Sykefravar.

9 Buchbinder R, van Tulder M, Öberg B, et al. Low back pain: a call for action. Lancet 2018;391:2384-8.
10 Albert HB, Sorensen JS, Christensen BS, et al. Antibiotic treatment in patients with chronic low back pain and vertebral bone edema (Modic type 1 changes): a double-blind randomized clinical controlled trial of efficacy. Eur Spine J 2013;22:697-707.

11 Dudli S, Fields AJ, Samartzis D, et al. Pathobiology of Modic changes. Eur Spine J 2016;25:3723-34.

12 Modic MT, Steinberg PM, Ross JS, et al. Degenerative disk disease: assessment of changes in vertebral body marrow with MR imaging. Radiology 1988;166:193-9.

13 Herlin C, Kjaer P, Espeland A, et al. Modic changes - their associations with low back pain and activity limitation: a systematic literature review and meta-analysis. PLoS One 2018;13:e0200677.

14 Bråten LCH, Rolfsen MP, Espeland A, et al. Efficacy of antibiotic treatment in patients with chronic low back pain and Modic changes (the aim study): double blind, randomised, placebo controlled, multicentre trial. BMJ 2019;367:I5654.

15 Lin C-WC, Haas M, Maher CG, et al. Cost-effectiveness of general practice care for low back pain: a systematic review. Eur Spine $J$ 2011;20:1012-23.

16 Lin C-WC, Haas M, Maher CG, et al. Cost-effectiveness of guidelineendorsed treatments for low back pain: a systematic review. Eur Spine J 2011;20:1024-38.

17 Storheim K, Espeland A, Grøvle L, et al. Antibiotic treatment in patients with chronic low back pain and Modic changes (the AIM study): study protocol for a randomised controlled trial. Trials 2017;18:596.

18 Herdman M, Gudex C, Lloyd A, et al. Development and preliminary testing of the new five-level version of EQ-5D (EQ-5D-5L). Qual Life Res 2011;20:1727-36.

19 Office of Health Economics. Valuing health-related quality of life: an EQ-5D-5L value set for England, 2016. Available: https://www.ohe. org/publications/valuing-health-related-quality-life-eq-5d-5l-valueset-england [Accessed 18 Nov 2016].

20 Drummond MF, Sculpher MJ, Torrance GW, et al. Methods for the economic evaluation of health care programmes. 3 edn. Oxford: University Press, Oxford, 2005.

$21 \mathrm{NMoHaC}$ Services. Principles for priority setting in health care summary of a white paper on priority setting in the Norwegian health care sector, 2016.

22 Statens Legemiddelverket. Covid-19, legemidler og medisinsk utstyr Available: http://legemiddelverket.no

23 Haukaas FS, Vøllestad NK, Robinson H, et al. Helseøkonomisk evaluering I fysioterapi. Fysioterapeuten 2015;10:22-7.

24 National Institute for Health and Care Excellence. NICE guidelines for low back pain and sciatica. Available: https://www.nice.org.uk/ guidance/ng59

25 Miyamoto GC, Lin C-WC, Cabral CMN, et al. Cost-Effectiveness of exercise therapy in the treatment of non-specific neck pain and low back pain: a systematic review with meta-analysis. Br J Sports Med 2019;53:172-81.

26 Wisløff T, Hagen G, Hamidi V, et al. Estimating QALY gains in applied studies: a review of cost-utility analyses published in 2010 . Pharmacoeconomics 2014;32:367-75.

27 Coretti S, Ruggeri M, McNamee P. The minimum clinically important difference for EQ-5D index: a critical review. Expert Rev Pharmacoecon Outcomes Res 2014;14:221-33.

28 Johnsen LG, Hellum C, Nygaard OP, et al. Comparison of the SF6D, the EQ5D, and the oswestry disability index in patients with chronic low back pain and degenerative disc disease. BMC Musculoskelet Disord 2013;14:148.

29 Salathé CR, Melloh M, Crawford R, et al. Treatment efficacy, clinical utility, and cost-effectiveness of multidisciplinary biopsychosocial rehabilitation treatments for persistent low back pain: a systematic review. Global Spine J 2018;8:872-86.

30 Appleby J. Crossing the line: NICE's value for money threshold. BMJ 2016;352:i1336.

31 Werner EL, Storheim K, Løchting I, et al. Cognitive patient education for low back pain in primary care: a cluster randomized controlled trial and cost-effectiveness analysis. Spine 2016;41:455-62.

32 van Dongen JM, Ketheswaran J, Tordrup D, et al. Health economic evidence gaps and methodological constraints in low back pain and neck pain: results of the research agenda for health economic evaluation (RAHEE) project. Best Pract Res Clin Rheumatol 2016;30:981-93.

33 Groll DL, To T, Bombardier C, Wright JG, et al. The development of a comorbidity index with physical function as the outcome. $J$ Clin Epidemiol 2005;58:595-602. 